\title{
Energy-saving processes simulation in reconstruction of educational institutions edifices
}

\author{
S.G. Sheina ${ }^{1}$, I. Y. Zilberova ${ }^{1}$, A.O. Vongay ${ }^{1, *}$ \\ ${ }^{1}$ Department of urban development and economy, Don State Technical University, Academy of \\ Construction and Architecture, 1 Gagarina square, Rostov-on-Don, 344000, the Russian Federation
}

\begin{abstract}
One of the high-priority directions in the development of the Russian and global economies is energy saving and reduction of exhaustible energy resources consumption. It is possible to make the existing urban development pool correspondent with the required energy efficiency class by way of reconstruction. Despite the fact that the said law entered into force in 2010, there is still a lack of methods of systematic development of energy-saving policies for educational institutions edifices within the framework of reconstruction. Methods applied separately for reconstruction and introduction of energy saving measures do not allow a simulation of acceptance of effective solutions for level enhancement of technical operation of the edifices. Methods of efficiency enhancement for the technological processes of edifices reconstruction are represented in this article for the first time; evaluation criteria for efficiency of technological processes in reconstruction of higher educational edifices have been developed; a method of criterion analysis has been applied taking the binding conditions of technologies introduction into consideration. The practical significance of the method developed has been proved by way of introduction thereof into the framework of reconstruction of the edifices of the higher educational institution.
\end{abstract}

\section{Foreword}

Under the current economic situation, the civil engineering market of Russia demonstrates a trend to reduce the construction of new objects. Nevertheless, the problems of energy efficiency of public edifices are becoming more and more pressing, especially after the enactment of the federal law FZ-261 "Of Energy Saving and increase of Energy Efficiency ...".

According to the said law, the operated edifices shall fall under the energy efficiency class no below C "Normal", but almost 80 of the deficits in Rostov Region belong to the D and E classes. Energy efficiency class enhancement for the existing edifices can be carried out within the framework of reconstruction. Despite the fact the issue of energy efficiency have since long enough become the issues of state importance there is still a lack of adequate methods of systematic development of energy-saving policies for public edifices

\footnotetext{
* Corresponding author: vao1090@gmail.com
} 
within the framework of reconstruction.

Methods applied separately for reconstruction and introduction of energy saving measures do not allow a simulation of acceptance of effective solutions for level enhancement of technical operation of the edifices.

Urgency of the issue is stipulated by the fact that the enhanced arrangement of technological processes in the course of reconstruction of edifices is one of the ways to provide for efficient solutions for improvement of the level of technical operation of the edifices granted the application of energy-saving measures. The solution of this problem is offered by means of an innovative method of arrangement efficiency enhancement for technical processes of reconstruction of public edifices with the use of energy-saving measures.

\section{Main problems of technological processes arrangement in reconstruction of educational institutions edifices}

\subsection{Peculiarities of energy-saving programs implementation in budget-funded institutions}

Analysis of rules and regulations in the sphere of energy saving and energy efficiency enhancement has shown that the normative framework in the Russian Federation is built by the federal laws, orders and resolutions of the Russian Federation Government, orders of the federal ministries, and other legal acts and documents. As the main regulatory act guiding the energy saving policy in the Russian Federation, the Federal Law No. 261 "Of Energy Saving and increase of Energy Efficiency ..." has been currently adopted.

The categories of entities for whom the compliance with the requirements to energy efficiency is mandatory have been determined by the law 261-FZ. Among such entities, there are budget-funded institutions.

According to the Russian Federation Government Decree No. 20 dd. January 25, 2011, the budget-funded institutions are included into the state information system for energy saving and enhancement of energy efficiency (EE)[1].

Now let us highlight the main peculiarities of the budget-funded organizations in the sphere of energy saving:

- Determination of indicators for calculation of key indicators values for the period till the year 2020 and adjustment of energy saving programs with consideration thereof;

- Conduction of works aimed at installation of instrument gauges at the budget-funded objects;

- Conduction of systematic energy inspections at the budget-funded objects;

- Periodic control over compliance with the legislative requirements in the sphere of energy saving, implementation of programs for energy saving.

Based on the analysis of normative documents, a conclusion can be made that in order to comply with the requirements of modern legislation to energy efficiency (EE) of the budget-funded institutions, a complex (program) method of measure-taking is necessary.

Funding of energy saving programs is yet another important aspect of budget-funded institutions operation.

Following are the peculiarities of funding of the budget institutions:

1) Sources of funding - measures taken within the federal state (municipal) institutions\$ these are implemented within the framework of current financing by the federal executive power authorities;

2) Utilization of saved funds - grant given for fulfillment of the state (municipal) task proceed to the current account of the budget-funded institutions. These are used by the 
budget-funded institutions within the limits of balances reflected on the individual accounts of such institutions without representation of documents confirming the occurrence of cash commitments. This allows to use the saved funds in the direction selected by the institution itself.

The funding of the energy efficiency programs in the budget-funded institutions is thus determined by the state for the period until the year 2020 . The funding is effected within the framework of the state program for energy efficiency and assumes the use of both budget and non-budget sources of funding.

\subsection{Analysis of technological processes arrangement in the course of reconstruction of educational institutions edifices}

Analysis of theoretical researches in the sphere of technological processes arrangement has shown that these issues are covered with sufficient fullness in the works of such scientists as V.A. Afanasyev, L.G. Dikman, A.A. Lapidus, Y.B. Monfred, V.I. Telichenko, T.N. Tsay, A.K. Schreiber, et al.

Reconstruction of educational institutions edifices has a number of specific peculiarities of conduction of works: limited time of works implementation, while the reconstruction is carried out without interruption of educational process in the period of minimal edifice utilization rate; limited field of operation due to implementation of works within the existing development pool; increased requirements to safety techniques, due to implementation of works in the operated building; limited funding.

The common drawback of all the mentioned works is the lack of theoretical research and practical advice as of assessment and choice of rational variants of technological processes arrangement in the course of reconstruction of edifices and buildings based on the certain terms of works implementation. In particular, such issues as possibility to simulate technological processes of building and installation works under preservation of educational process have not been discussed for the educational institutions.

Pursuant to the requirements of the current Russian legislation, energy-efficient technologies must be utilized in the course of reconstruction of public edifices and buildings. Sometimes this can become one of the reasons for reconstruction if, for instance, it is necessary to provide for the necessary value of thermal transmission resistance of the walls in connection with the alternation of normative values. [1].

Such researchers as V.G. Gagarin, L.A. Danilov, A.N. Dmitryev, V.I. ledenev, V.V. Malyavina, Y.A. Matrosov and others have been dealing with the developments in the sphere of energy efficiency for various branches of economy.

The works of the mentioned researchers reflect the methods of implementation of energy-saving and energy-efficient measures (ESEM) within the framework of the "State Enerfy Efficiency Program till 2020", and technical and economical efficiency evaluation methods for implementation results of such measures.

On the basis of analysis presented in the works by I.A. Bashmakov and V.I. Bashmakov, Sh. G. Zinganshin, S.B. Sborschikov et al., it has to be noticed that the energy saving policy in the Russian Federation still does not cover all the main spheres of development economy. ESEM fulfillment is not taken into account in the course of fulfillment of works for reconstruction of buildings as the ESEM are the part of other programs for development of Russian economy and entail sufficient expenditures in the course of reconstruction.

Besides, in order to comply with the requirements made by the current legislation in the sphere of energy saving and enhancement of energy efficiency for the budget-funded institutions, a complex (program) method of measures implementation is necessary.

The main evaluation criteria for the technological processes in the course of 
reconstruction of buildings under consideration of ESEM are:

- Duration of works;

- Labor input;

- Cost of works;

- Energy efficiency of the building;

- Efficiency of energy saving measure.

\section{Method development of the resource and technological model formation}

\subsection{Principal technological processes of public buildings reconstruction}

\subsubsection{Technological processes of public buildings reconstruction}

Depending on the scope and nature of the measures implemented, the reconstruction of the building or edifice can be partial or complete. The possibility and expediency of either complete or partial reconstruction of the building are determined by the two main reasons:

1) Depreciation rate of the main bearing constructions (walls and floor slabs);

2) Compliance of the building plan and amenities with the modern requirements and a possibility to use the external sanitary utilities without substantial rearrangement.

3) In case of complete (complex) reconstruction of the building, durability and amenities of the building are also enhanced at the same time (including, thermal protection improvement). The complete (complex) reconstruction is mostly expedient provided the good state of walls and foundation (depreciation rate below $40 \%$ ).

Following the complete reconstruction, the building shall comply with the modern operating requirements, sanitary and household requirements, design requirements, energy efficiency requirements, and other norms to the fullest possible extent, and in some cases, even exceed those.

The main groups of reconstruction works include:

1) reinforcement of constructions

2) replacement of constructions

3) perforation and boring of holes and apertures in the constructions. Filling of holes, gains and grooves.

4) topping-out and extension of buildings

5) reconstruction of buildings

6) dismantling of structures

7) demolition of buildings

All reconstruction works including topping-out may be carried out as an independent reconstruction method or be a part of the accompanying measures for complex reconstruction of the entire building.

\subsubsection{Principal energy saving measures in the course of reconstruction of buildings and edifices of the educational institutions}

The requirements contained in the Federal Law No. 261-FZ dd. November 23, 2009 and the SRO standards are made to the energy saving measures; the main requirements are:

1. Recommended measures including the proposed results of implementation thereof must be easily comprehendible for the head, the engineering and technical team, and managerial staff charged with the implementation of the measures; 
2. Measures must be specific and targeted;

3. Measures must be oriented on the existing and actually available methods and possibilities of implementation thereof;

4. Implementation of the measures must allow for the assessment of the deliverables by relatively simple methods;

5. Measures must obligatorily take the specific social and economical situation at the enterprise into account;

6. Offering several alternative variants of measures is desirable.

Compliance with these requirements requires the knowledge of, and expertise in classification of measures, and a guidance under the method of classification thereof.

At IV Energy Forum "Energy Efficiency Standards: Educational and Scientific Organizations", the Russian Federation Ministry of Education and Science presented a list of recommended ESEM for educational organizations including the higher educational institutions.

Based on the considered technological processes (TP's) of educational institutions edifices reconstructions, and the ESEM list recommended by the Russian Federation Ministry of Education and Science, a list of technological processes carried out in the course of reconstruction with regard to the ESEM is being formed. Technological processes carried out in the course of educational institutions edifices reconstructions must comply with the modern energy saving requirements.

\subsection{Resource and technological models of the principal energy saving measures in the course of reconstruction of the educational institutions}

The buildings reconstruction works comprise complex technological processes and a multitude of variants of implementation thereof. A technological process is chosen on the basis of the existing technologies for each type of works. Each technology is assigned a sequential number $i=\{1,2, \ldots, n\}$.

Rational choice of technological process for carrying out one type of works or another on the pre-design stages of civil engineering production from the economic, material and resource expediency viewpoints is made on the basis of the resource and technological model (RTM) which essentially is a specially prepared (aggregated) set of material and labor resources invariable within a long period of time which is formed on the basis of data about representative objects [2].

The data on the representative object allow to simulate the most rational arrangement and technological solutions of civil engineering system retrieved by means of trial design and detection of alternative solutions that comply the most with the specific production conditions.

The resource and technological model is comprised by two blocks:

1. Resources block, which contains specially elaborated rated volumes of materials and products in physical terms, and the normative value of labor costs of the employees engaged in building and installation works.

2. Cost block, which includes the cost assessment of the volume unit of a resource (resource price) and the complete resource volume cost. The cost assessment block contains the values of resource costs for the reference period.

The basis for forming of resources block is the definition of material resources application volume in the course of reconstruction works implementation at the representative objects depending on the technological process.

The total volume of applied resources is determined by means of fulfilled works listing $\left(\sum a_{i}\right)$ for the object, and determination of volume of materials, machinery and mechanisms applied as per type of works or as per object as a whole. According to the valid state cost 
estimate standards, each work $a_{i}$ is separated into the list of resources: materials, machinery, mechanisms, labor costs; also, the duration of the works $a_{i}$ and technical process $T P i$ as a whole are established.

For the homonymous objects, the resource indicators undergo a procession, and then used for the RTM formation for the purpose of work implementation costs determination with the use of statistical istrumentarium

The cost block is formed by means of determination of the average weighted value for the group of materials as per basic price level for the materials in the region under consideration.

\subsection{Assessment of arrangement efficiency of the technological processes in the course of reconstruction of the buildings and edifices as per economic and energy criteria}

There is a significant number of methods and models used in order to solve the problems of efficiency assessment for the technological processes arrangement (TPA) in the course of reconstruction [3]. Unfortunately, the modern researches lack recommendations as of the choice of top-priority technical process for specific kind of work. For this purpose, the evaluation of efficiency research was made for TPA, and criterion analysis and the weight coefficient $(\mu)$ were chosen as the scientific research methods.

Quite naturally, a question arises what criteria are the defining ones for the choice of the most effective technological process. To solve this problem, the analysis of peculiarities of educational institutions in the course of arrangement of TP reconstruction, and the analysis of requirements to energy saving and energy efficiency enhancement were carried out. As a result, a set of criteria taken into account in determination of the TP priority was compiled, which comprises 2 groups:

1) economic criteria of TP efficiency evaluation;

2) energy-related criteria of the TP efficiency evaluation.

The range of economic criteria included:

1) expenditures of technological process implementation within the range of basic process as of January 01, 2001;

2) expenditures of technological process implementation at the current price level;

3) duration of works;

4) labor input into works.

The following criteria are energy-related:

5 ) energy efficiency of TP in natural volumes;

6) energy efficiency of TP in monetary terms;

7)payback period.

The energy efficiency of the technological process supposes the use of simplified calculation scheme without consideration of time factor (discounting) as the evaluation of each measure with discounting will not be credible enough, and the process itself is quire durable and labor intensive.

The TPA efficiency enhancement procedure is essentially a multi-criterion task in which several factors characteristic of the technological process under specific limitations have to be considered at the same time.

In order to solve this problem, it is possible to use the criterion analysis method to determine the weight coefficient $\mu$ and to carry out an expert evaluation.

On the first stage of criterion analysis, a criterion matrix $Q(i ; j)$ is prepared, where $\mathrm{i}=\{1,2 \ldots \mathrm{n}\}, \mathrm{j}=\{1,2, \ldots \mathrm{m}\}$ or 


$$
Q=\left(\begin{array}{cccc}
q_{11} & q_{12} & \ldots & q_{1 m} \\
q_{21} & q_{22} & \ldots & q_{2 m} \\
\ldots & \ldots & \ldots & \ldots \\
q_{n 1} & q_{n 2} & \ldots & q_{n m}
\end{array}\right) Q=\left(\begin{array}{cccc}
q_{11} & q_{12} & \ldots & q_{1 m} \\
q_{21} & q_{22} & \ldots & q_{2 m} \\
\ldots & \ldots & \ldots & \ldots \\
q_{n 1} & q_{n 2} & \ldots & q_{n m}
\end{array}\right)
$$

Where each line $\mathrm{i}$ corresponds to a technological process $\mathrm{TP}_{\mathrm{i}}$, each column $\mathrm{j}$ corresponds to a specific criterion, and $\mathrm{q}_{\mathrm{ij}}$ is a value of the criterion $\mathrm{j}$ of the $\mathrm{TP}_{\mathrm{i}}$. Thus, we obtain the table 1 .

Table 1. Overview of the criterion assessment table of the technological process.

\begin{tabular}{|c|c|c|c|c|}
\hline & Criterion 1 & Criterion 2 & $\ldots$ & Criterion $\mathrm{m}$ \\
\hline $\mathrm{TP}_{1}$ & & & & \\
\hline $\mathrm{TP}_{2}$ & & & & \\
\hline$\ldots$ & & & & \\
\hline $\mathrm{TP}_{\mathrm{n}}$ & & & & \\
\hline
\end{tabular}

The next stage assumes a verification of compliance of the criteria $\left(q_{i j}\right)$ with the limitation conditions and exclusion conditions for the process TPi in case of failure to fulfill the condition (2)

where $\mathrm{Q}_{\text {jmax }}$ is the limit value of the criterion $\mathrm{q}_{\mathrm{j}}$.

$$
\mathrm{q}_{\mathrm{ij}} \leq \mathrm{Q}_{\mathrm{jmax}},
$$

Thus, the number of the excluded TP $(\mathrm{N})$ can be $\mathrm{N}=[0 ; \mathrm{n}]$. in this case, the dimension of the matric will be $n-\mathrm{N} \times \mathrm{m}$.

Further, an expert evaluation of the technological processes TPi is carried out.

One person acts as an expert, or one ECM (computer) is used for scoring. The score is attributed by the criterion value $\mathrm{q}_{\mathrm{j} \text { within }}$ the range from 1 to $(\mathrm{n}-\mathrm{N})$ in order of priority increase of the criterion.

The final stage assumes a calculation of the weight coefficient $\mu$ calculation for the TPi and verification of the calculation.

The weight coefficient $\mu$ is calculated under the formula (3):

$$
\mu_{\mathrm{i}}=\frac{\boldsymbol{\Sigma} g_{i j}}{\boldsymbol{\Sigma} \boldsymbol{\Sigma} g_{i j} g_{i j}}
$$

where $\mu_{\mathrm{i}}$ is the weight coefficient, $g_{i j}$ is the individual indicator value represented in scoring as per each $\mathrm{j}$-th characteristic.

Verification: $\sum \mu_{\mathrm{i}}=1$; if the condition is not fulfilled, calculation verification is necessary.

Based on the criterion analysis and calculation of the weight coefficient, the expert draws a conclusion on the most appropriate technological process (TPi) proposed for introduction.

Economic assessment of the TP arrangement efficiency in course of the public buildings reconstruction is made as per the following efficiency indicators: Net discounted income (NDI), Profitability index (PI), Payback period $\left(\mathrm{T}_{\text {ок }} \mathrm{PbP}\right)$.

On the basis of the above calculations, a simulation algorithm for TP arrangement in the course of reconstruction of public buildings under consideration of the ESEM was developed (see fig. 1). 


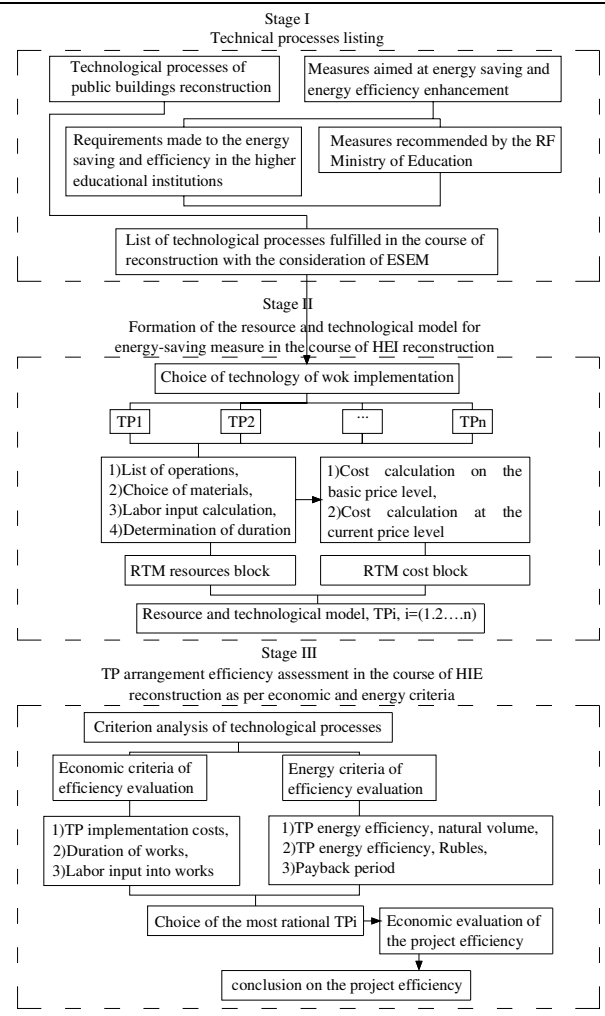

Fig. 1. RTM forming algorithm.

The resource and technological model allows for an optimization of the civil engineering production, maximal level of adaptation of the object to the specific conditions of the region, and analysis of investment efficiency on the preliminary design stages. Nevertheless, the RTM forming method has its advantages and disadvantages, too. Having a high degree of assessment probability, it does at the same time require a processing of a vast database on the resources for the representative objects built in the specific region. Economic assessment of the technological process efficiency on the basis of which a conclusion on the expediency of reconstruction is made, is an important stage of technological processes optimization.

\section{Conclusions}

On the basis the analysis of regulatory documentation, it can be concluded that in order to comply with the requirements of modern legislation in the field of energy saving and increase of energy efficiency of educational institutions, a comprehensive (program) method of implementation of measures is needed.

Funding of the energy saving programs and energy efficiency enhancement is defined by the state for the period until the year 2020.The funding is carried out within the framework of the state program and supposes the utilization of both budget and non-budget sources of funding. Such issues as the possibility of technological processes simulation for building and installation works without interruption of the educational process have been considered herein.

The main assessment criteria for technological processes in the course of buildings reconstruction with consideration of the ESEM are:

- Duration of works;

- Labor input into works;

- Cost of works; 
- Energy efficiency of the building;

- Efficiency of energy-saving measure taken.

It was proposed to increase the efficiency of technological processes arrangement in the course of reconstruction of buildings by means of use of the resource and technological modeling and to evaluate the efficiency of technological processes by economic and energy parameters using the criterion analysis.

On the basis of the above calculations, an algorithm of technological processes simulation in the course of public buildings reconstruction with the consideration of ESEM was elaborated. The resource and technological model allows for an optimization of the civil engineering production, maximal level of adaptation of the object to the specific conditions of the region, and analysis of investment efficiency on the preliminary design stages. Nevertheless, the RTM forming method has its advantages and disadvantages, too. Having a high degree of assessment probability, it does at the same time require a processing of a vast database on the resources for the representative objects built in the specific region.

Economic assessment of the technological process efficiency on the basis of which a conclusion on the expediency of reconstruction is made, is an important stage of technological processes optimization.

Practical implementation of the elaborated method of TP arrangement efficiency enhancement has taken place in the course of reconstruction of the public buildings of Academy of Construction and Architecture under the Don State Technical University. By using the method of criterion analysis, the most effective technological process of thermal protection improvement was chosen for the buildings. Economic assessment of the project efficiency was carried out.

This article has been prepared with the support of the Russian Foundation for Fundamental Research. Copyright certificate for registration of software on the ECM was duly obtained.

\section{References}

1. B.N. Volynsky, Constructive solutions for energy-saving building, Energy-saving No. 3, 67 (2001)

2. V.G. Gagarin, Regarding the rationale for increasing the thermal protection of the enclosing structures of buildings, Stroyprofil, No. 1, 21-23 (2010).

3. Grabovy, P.G., Kharitonov, V.A., Reconstruction and renewal of the existing urban development: A textbook. $2^{\text {nd }}$ ed., revised. Moscow, Prospekt (2013)

4. I.Y. Zilberova, System-flow arrangement of civil engineering production in the course of reconstruction of residential houses, Author's abstract form $\mathrm{PhD}$ Tech. thesis, Rostov-on-Don, (2000)

5. S.G. Sheina, N.D. Cherednichenko, A.O. Vongay, The choice of the most effective option for increasing the thermal protection of buildings of higher educational institutions by the use criterion analysis method, Bulletin of Construction Machinery No. 9, 55-58 (2009).

6. S. Sheina, A. Khamavova Technique for the Russian Federation regional territories assessment used to create industrial parks network J. Procedia Engineering 150, 19601965 (2016) 